\title{
The EU ETS and its companion policies: any insight for China's ETS?
}

\author{
Stefano F. Verde, ${ }^{1}$ Giulio Galdi, ${ }^{1}$ (D) Isabella Alloisio, ${ }^{1}$ and Simone Borghesi ${ }^{1,2 \star ~(D) ~}$ \\ ${ }^{1}$ Florence School of Regulation - Climate, European University Institute, Florence, Italy and ${ }^{2}$ Department \\ of Political and International Sciences, University of Siena, Siena, Italy \\ ${ }^{*}$ Corresponding author. E-mail: simone.borghesi@eui.eu
}

(Submitted 12 February 2020; revised 27 September 2020; accepted 15 November 2020; first published online 8 March 2021)

\begin{abstract}
This paper analyses the role that companion policies have had in the reduction of emissions regulated by the EU Emissions Trading System (EU ETS) and the related policy interactions, with a view to identifying relevant insights for China's forthcoming Emissions Trading System (ETS). The investigation rests on: (a) the observation of the EU's and China's ETSs and policy mixes; (b) economic theory concerning companion policies and ETS design; and (c) empirical ex-post evidence from the EU ETS. Three main conclusions emerge from the analysis. First, China's ETS, while not imposing a fixed cap on emissions, will not be immune to waterbed effects of companion policies. Second, the European experience stresses the importance of making explicit the objectives pursued by companion policies, and of balancing policies for innovation and policies for adoption of low-carbon technologies. Third, in the presence of a major market surplus, only permanent adjustments to allowance supply can be effective in raising prices.
\end{abstract}

Keywords: emissions trading; China's ETS; companion policies; EU ETS; waterbed effect; policy interactions

JEL classification: H23; N50; Q52; Q54; Q56

\section{Introduction}

Since the launch of the EU Emissions Trading System (EU ETS), in 2005, the diffusion of large-scale emissions trading systems (ETSs) for climate change mitigation has been confined to advanced economies, with the exceptions of Kazakhstan and, recently, Mexico. Along with the EU ETS, which currently remains the world's largest ETS in operation, other well-established systems include those of New Zealand, South Korea, Switzerland, California, Quebec and the Regional Greenhouse Gas Initiative, which involves several north-eastern US states. There is little doubt, however, that we will see in the future a growing number of ETSs in developing economies. Under the Paris Agreement, almost all countries in the world are committed to achieving climate mitigation targets as specified in their Nationally Determined Contributions. A few countries with 
developing economies have already started setting up their own ETS or have been considering doing it. Mexico's pilot ETS started in January 2020 and China's national ETS is expected to become operational by mid-2021. The ETSs of Colombia and Ukraine are under development, while ETSs are under consideration in Brazil, Chile, Indonesia, Pakistan, Thailand, Turkey and Vietnam (ICAP, 2020).

In the last few years, the development of China's forthcoming ETS has attracted much attention worldwide from policymakers, industry, investors, researchers and civil society. Both the role of China in the fight against climate change, as being responsible for about a quarter of global greenhouse gas (GHG) emissions, and the size of China's ETS, which will be about double that of the EU ETS, explain such a level of interest and expectation on the part of the international community. China's ETS also deserves special attention because it can become a blueprint for other ETSs in developing economies. Indeed, it exemplifies how design features that are standard among existing ETSs can be adapted to specificities of developing economies. Notably, these specificities relate to: (a) higher and more uncertain rates of economic growth, which implies that determining appropriate long-term emission caps can be an improbable task; and (b) highly regulated electricity markets inhibiting the pass-through of carbon costs. ${ }^{1}$

The history of emissions trading demonstrates how important learning-fromexperience is for improving the functioning of an ETS (Schmalensee and Stavins, 2017). The very creation of the EU ETS was inspired by the $\mathrm{SO}_{2}$ Allowance Trading Scheme in the US, and the failures and successes of the EU ETS, so to speak, have provided lessons of use to other systems. Likewise, significant developments in other ETSs offer learning opportunities to other systems. One such development, for example, is the linkage of the ETSs of California and Quebec. Today, the question arises of which lessons or insights from well-established ETSs can be useful to the new followers in developing economies.

With a view to identifying insights that can be relevant to China's ETS, this paper analyses the role that companion policies have had in the reduction of emissions regulated by the EU ETS and the related policy interactions. We use the term 'companion policies' in its broadest sense to indicate any instrument or measure that reduces emissions regulated by an ETS. This includes, among others, emission efficiency standards, subsidies to innovation and adoption of renewable energy technologies, energy and carbon taxes, as well as mandated shutdowns of polluting plants. Reference to specific companion policies is made whenever this serves the analysis well. Companion policies are an important topic in emissions trading and carbon pricing more generally because, depending on how they are calibrated, they reduce or increase the cost of abatement compared to carbon pricing alone. In addition, by reducing (regulated emissions and, hence,) allowance demand, companion policies interact with an ETS, which has its own implications. First, unless allowance supply adjusts in response to companion policies, these do not actually produce additional abatement, what is known as the 'waterbed effect'. Second, unanticipated abatement by companion policies reduces allowance prices and, thereby, potentially deteriorates the long-term (or dynamic) cost-effectiveness of an ETS - unless, again, allowance supply adjusts.

Some important design differences distinguish the EU ETS and China's ETS. Notably, while the first is a classic cap-and-trade system, the second imposes a relative cap on

\footnotetext{
${ }^{1}$ Other possible specificities of developing economies, which may have implications for the design or implementation of ETSs, include poor statistical data, lack of policy coordination, ineffective law enforcement, etc. Arguably, the specific design of ETSs for developing economies is an underdeveloped research area (Boute, 2017; Acworth et al., 2018; De Gouvello et al., 2019; Goulder et al., 2019).
} 
emissions and it effectively is a tradable performance standards system. Nevertheless, we find that the use of companion policies poses opportunities and risks that are similar for the two ETSs. Insights from the European experience are thus transferable to the Chinese context. Our investigation rests on the observation of the EU's and China's ETSs and the respective policy mixes, on economic theory concerning companion policies and ETS design, and on relevant empirical evidence from the EU ETS.

The rest of the paper is structured as follows. Section 2 describes the EU's and China's ETSs and the respective policy mixes. Section 3 provides the theoretical background. Section 4 reviews the EU ETS empirical evidence. Section 5 discusses the insights for China's ETS. Section 6 concludes.

\section{The EU's and China's ETSs and their companion policies}

The present section describes the EU ETS and China's ETS as well as the respective wider policy mixes. A factual account of EU and Chinese policies is needed to understand theoretical references, empirical evidence and the authors' views presented in the rest of the study.

\subsection{Emissions trading and companion policies in the EU}

\subsubsection{The EU ETS}

The EU ETS imposes an absolute cap on $\mathrm{CO}_{2}$, nitrous oxide and perfluorocarbons emissions from over 11,000 heavy energy-using and electricity-generating installations ${ }^{2}$ in the EU, Norway, Iceland and Liechtenstein, as well as from flights within the region. About 45 per cent of the EU's overall GHG emissions are currently covered by the EU ETS. The cap declines over time by a linear reduction factor so that by the end of Phase III (2013-2020), regulated emissions will have decreased by at least 21 per cent compared to 2005. By the end of Phase IV (2021-2030), under current rules, they will have decreased by at least 43 per cent.

The rules governing the EU ETS have evolved considerably over time, partly as a result of policy learning-by-doing and partly in response to unanticipated events, including first and foremost the consequences of the Great Recession. The first major changes to the EU ETS were brought in with the reform for Phase III. The overarching institutional innovation was the centralisation of the system. The cap is now determined at the EU level (rather than being the sum of national caps) and a single set of rules governs allowance allocation. The regime of allowance allocation radically changed too, with auctioning becoming the default allocation method for the electricity sector and benchmarked free allocation applying to the others (Verde et al., 2018). In 2015, the establishment of the Market Stability Reserve (MSR) was a key addition to the EU ETS, as it introduced flexibility in allowance supply.

The MSR is a rule-based mechanism for addressing imbalances of the allowance market caused by unanticipated exogenous changes in regulated emissions and, thereby, allowance demand. The need for such a mechanism became apparent after the economic crisis, which slashed emissions and, as a result, allowance demand and prices plummeted. Starting in January 2019, the MSR withdraws allowances from future auctions when

\footnotetext{
${ }^{2}$ Regulated activities include combustion of fuels in installations with a total rated thermal input exceeding 20MW, the refining of mineral oil, and the production of steel, iron, aluminium, cement, lime, glass, ceramics, paper, acids and bulk organic chemicals.
} 
market surplus ${ }^{3}$ exceeds a given thresholds (833 million allowances) and, conversely, it increases auction volumes when market surplus drops below a lower threshold (400 million allowances).

In 2018, the reform for Phase IV marked a new important change in the evolution of the EU ETS. The reform had three main objectives: strengthening the price signal by tightening the cap and by enhancing the MSR, better targeting free allocation, and establishing new funding mechanisms for low-carbon innovation and energy sector modernization in lower-income member states. Focusing on the MSR, the mechanism was enhanced in two ways. First, the intake rate, which determines the number of allowances withdrawn and stored in the reserve, was doubled from 12 to 24 per cent of market surplus. This higher rate will only apply in the period 2019-2023. Second, as of 2023, allowances in the reserve will be limited to the previous year's auction volume through the cancellation of those in excess. Importantly, the cancellation mechanism reduces the cumulative cap. ${ }^{4}$

\subsubsection{The EU's policy mix}

Most climate and energy policies currently in force in the EU stem from the 2020 Climate and Energy Package (C\&EP). Adopted in 2009, the C\&EP set three main targets to be achieved by 2020: (a) a 20 per cent reduction in GHG emissions relative to 1990 levels; (b) a 20 per cent share of energy from renewable energy sources (RES) in final energy consumption; and (c) a 20 per cent reduction in total energy consumption relative to a business-as-usual scenario. ${ }^{5}$ As the EU ETS only covers about half of the EU's GHG emissions, the Effort Sharing Decision (ESD) set national targets for emission reductions in the non-ETS sector, i.e., all economic sectors not covered by the EU ETS. These targets, which range between -20 per cent (from 2005 levels) for the wealthiest member states and +20 per cent for the least wealthy, add up to a 10 per cent reduction in the EU's overall emissions. It is the responsibility of member states to devise and implement policies to reach their targets. So far, all member states have been compliant with their ESD obligations, in a few cases thanks to the use of intra-EU flexibility mechanisms.

As with the ESD targets for emission reductions, member states were assigned binding targets for their RES share in final energy consumption, differentiated on the basis of GDP per capita, but also depending on the initial RES share and on the potential for increasing it. The targets differ widely, ranging from 10 per cent (Malta) to 49 per cent (Sweden). Member states are responsible for the policies for accelerated RES deployment, not only in the electricity sector but also in transportation and in the heating and cooling sector. A wide array of instruments promoting RES production, including feedin tariffs, green certificates, tenders and investment subsidies, have been implemented throughout Europe. In 2018, the share of RES in gross final energy consumption reached 18 per cent at the EU level, while 12 members states had already achieved their own targets (EEA, 2019).

\footnotetext{
${ }^{3}$ In EU ETS legislation, market surplus is the 'Total Number of Allowances in Circulation', which is defined as the difference between the cumulative amount of allowances available for compliance at the end of a given year, and the cumulative amount of allowances effectively used for compliance with the emissions up to that same year.

${ }^{4}$ For ex-ante analyses of the MSR in its original version and in its current (enhanced) version, see, respectively, Perino and Willner (2016) and both Perino and Willner (2017) and Perino (2018).

${ }^{5}$ Unlike the first two, the third target is not legally binding.
} 
With a view to meeting the energy efficiency (EE) target, member states have to comply with a few pieces of EU legislation, notably the eco-design directive, which sets minimum efficiency requirements for energy-related products (e.g., light bulbs, boilers), and the energy labelling regulation. Concerns that the EE target was going to be missed led the EU to also adopt the Energy Efficiency Directive (European Parliament and Council, 2012). The Directive more precisely quantified the energy consumption target, which sets a limit of 1474 Mtoe for primary energy and 1078 Mtoe for final energy. It also defined a common framework for promoting $\mathrm{EE}$ and it set binding targets in specific areas, notably in the renovation of public buildings and smart metering for residential electricity and heat consumption. In 2018, primary energy consumption and final energy consumption were, respectively, 4.9 and 3.2 per cent above the 2020 targets (Eurostat, 2020). Both indicators, however, will get closer to the 2020 targets given the impact of the Covid-19 pandemic on the economy (McWilliams and Zachmann, 2020).

The EU's climate and energy objectives for the next decade are to be found in the 2030 Climate and Energy Framework, whose structure closely resembles that of the C\&EP. The overall GHG target is a 40 per cent reduction in emissions (from 1990 levels), again to be achieved through the EU ETS and national policies for the non-ETS sector. Overall emissions from the non-ETS sector must be cut by 30 per cent relative to 2005 levels, with national targets set by the Effort Sharing Regulation. The 2030 RES target is a 32 per cent share of final energy consumption, not broken down by member state: it is an EU-wide target, to be achieved through coordinated action. As to EE, the target is a 32.5 per cent reduction in energy consumption relative to a business-as-usual projection.

Today, as part of the European Green Deal, EU climate policy is undergoing a relaunch which is unprecedented in its scope and ambition. A cornerstone of the Green Deal, which is a top priority for the current European Commission, is the achievement of climate neutrality for the continent by 2050 (European Commission, 2018, 2019). The 2030 target for overall GHG emissions has not yet been officially set, but the reduction in emissions is expected to be no less than 55 per cent relative to 1990 levels. For the EU ETS, this implies a further tightening of the cap over Phase IV. An extension of the EU ETS to other sectors, notably shipping, road transport and buildings, is also under consideration.

\subsection{Emissions trading and companion policies in China}

\subsubsection{China's ETS}

China's experience with emissions trading started in 2011, when the government identified the five cities of Beijing, Tianjin, Shanghai, Chongqing and Shenzhen and the two provinces of Hubei and Guangdong for pilot ETSs. These pilots became operational between 2013 and 2014. In 2016, the province of Fujian launched its own ETS, thus becoming the eighth operational pilot. Regulated firms collectively account for about 6 per cent of China's total $\mathrm{CO}_{2}$ emissions. The pilots provide a variety of ETSs as they have different design features from one another. These include: the nature of the emission reduction targets $^{6}$; the rules for allowance allocation; the scope of the system; the provisions for market stability; and the use of offset credits for compliance purposes.

\footnotetext{
${ }^{6}$ All Chinese ETS pilots have relative caps, i.e., targets for carbon intensity. However, the city of Shenzhen also committed to peak carbon emissions by 2022 .
} 
The diversity of the pilots and the experience accumulated through their implementation have been instrumental in the setup of the national ETS. ${ }^{7}$

Announced in 2017, China's ETS is expected to be launched by the end of 2020 (ICAP, 2020) and to be operational by mid-2021. Emission allowances will be freely allocated to subject firms in the electricity sector, which will be the only sector covered by the system in its first phase. Other sectors, including petrochemicals, chemicals, building materials, steel, nonferrous metals, paper and domestic aviation, will be covered at a later stage. Importantly, China's ETS will not impose an absolute cap on overall emissions - for the time being at least - but rather a series of emission efficiency standards for different products and processes. In other terms, China's ETS will not be a cap-and-trade system, like most existing ETSs, including the EU ETS. Rather, it will be effectively a tradable performance standards system. Accordingly, every year, each regulated firm will receive ex-post an allocation of emission allowances calculated by multiplying its annual output by the relevant efficiency standard or benchmark. Allocations will exceed emissions for firms operating below the benchmark (i.e., more efficient than the standard), and so these will be net sellers of allowances; by the same token, those operating above the benchmark will be net buyers. Moreover, as with any allocation system whereby allowances are granted based on output, the price of the allowances will act, at the same time, as a tax on emissions and as a subsidy to output (Fischer, 2001).

At the time of writing, the benchmarks for the first phase of China's ETS have not yet been defined (IEA, 2020). It is, however, likely that three benchmarks differentiated by fuel type (conventional coal, unconventional coal, and gas) will initially apply to electricity generation. ${ }^{8}$ Furthermore, after an initial phase in which only electricity generators will be covered, China's ETS will also apply to indirect emissions of grid operators and of large electricity consumers in the sectors covered by the system. This triple regulation of emissions - which involves electricity generators, grid operators and large electricity consumers - is explained by the limited possibility of transferring costs in a still heavilyregulated electricity market. ${ }^{9}$ As grid operators and electricity users would hardly be incentivised to reduce energy losses and energy use, their inclusion in the ETS is a way to establish these incentives.

\subsubsection{China's policy mix}

Beyond emissions trading, China uses a broad mix of energy and climate policies which stem from the Five Year Plans (FYPs) for the country's social and economic development (Li and Taeihagh, 2020). The FYPs set national objectives, but provincial authorities are responsible for identifying and implementing the policies to achieve them and they may, in turn, assign targets to lower government levels. The political accountability of local leaders is high; so much so that on occasions provincial authorities have ordered the

\footnotetext{
${ }^{7}$ For comparative reviews of the Chinese pilot ETSs, see Deng and Zhang (2019), Wang et al. (2019, 2020). For an evaluation of their environmental effectiveness, see Zhang et al. (2019).

${ }^{8}$ The multiplicity of benchmarks means that distributional effects of the ETS across regions - a major concern for Chinese authorities - are mitigated. Indeed, as the generation mix of electricity supply significantly varies within China, the application of a single uniform benchmark would result in disproportionate compliance costs for certain regions. As Goulder et al. (2019) show, however, the application of multiple benchmarks comes at a cost in terms of the reduced cost-effectiveness of the system.

${ }^{9}$ Recent reforms of the electricity sector, however, have allowed for market-determined production prices. According to Goulder et al. (2019), in 2018, almost one-third of the electricity consumed in China was sold at market-clearing prices.
} 
temporary shutdown of power plants to avoid the risk of non-compliance with national EE targets (Sandalow, 2019). ${ }^{10}$ More broadly, in recent years energy and climate policies have undergone a process of centralisation. Notably, the Chinese government has shown favour to national regulation, with direct and homogeneous effects across the country, over delegation to local authorities for the achievement of regional targets. The centralisation process has been paralleled by increasing commitment toward tackling local environmental problems and climate change. This commitment has moved along four phases which correspond to different types of targets coinciding with the last four FYPs: non-binding targets; energy-intensity targets; carbon-intensity targets; and emission-peak targets (Gallagher and Xuan, 2019).

Over the past fifteen years, the Chinese government has provided strong support to RES electricity. The first important initiative was the Renewable Energy Law, in 2005, which among other things guaranteed that all RES electricity injected into the grid would be purchased by grid companies. In 2009 and 2011, feed-in tariffs for wind and photovoltaic (PV) generation were introduced. ${ }^{11}$ With the 13th FYP (2015-2020), the government intensified its efforts in RES deployment and committed to a 20 per cent share of renewables in primary energy consumption. To this end, it set an investment objective of RMB 2.5 trillion by 2020 . VAT cuts or exemptions for RES equipment deployment or imports were also provided, on top of a pre-existing subsidy for buildingintegrated PV. Further, the government committed to reducing electricity generation from its least-efficient coal plants, mandating their substitution by $2020^{12}$ and halting the construction of new ones in provinces with an extant capacity surplus (Gallagher and Xuan, 2019).

As to EE policies, the approach of the Chinese government mainly consists of several efficiency standards which apply nationwide. The One Hundred Energy Efficiency Standard Promotion Program sets sector-specific efficiency standards for eight energyintensive sectors. ${ }^{13}$ The same sectors are subject to higher electricity prices set by the Differential Electricity Price Policy, with the premium varying depending on firms' technological category (Hu et al., 2012). The government also introduced EE labelling and standards on many commercial goods (household appliances, vehicles, etc.). In addition, it defined national energy reduction targets, whose achievement is delegated to provincial authorities. The 13th FYP, for example, sets energy and emissions reduction targets for vehicles (respectively 16 and 18 per cent, relative to 2005 levels), ships (20 and 22 per cent) and urban transport ( 26 and 30 per cent), to be achieved by the end of 2020 .

\section{Relevant economic concepts}

\subsection{Rationales for companion policies}

Economists tend to emphasise that carbon pricing, whether in the form of carbon taxation or emissions trading, reduces GHG emissions at minimum cost. The underlying logic is that carbon pricing equalises marginal abatement costs across subject polluters,

\footnotetext{
${ }^{10}$ In 2016 , several political authorities were arrested for failing to meet national environmental targets (Sandalow, 2019).

${ }^{11}$ The feed-in tariff rate has been gradually lowered over time because of reduced deployment costs.

${ }^{12} 20 \mathrm{GW}$ of coal-fired power units are expected to be eliminated before the end of 2020 .

${ }^{13}$ It was amended in 2017 by the Program for the Construction of an Energy-saving Standard System.
} 
thus minimising the cost of achieving a given abatement level. ${ }^{14}$ The equimarginal principle, however, ignores aspects of the real world which provide economic or political-economic rationales for the use of carbon pricing together with companion policies.

A first consideration is that companion policies often exist for reasons that transcend climate mitigation: cutting emissions is not necessarily their sole purpose or even the main one. Say, policies supporting renewable energy or EE may also pursue objectives concerning security of energy supply, local pollution reduction or industrial development. Thus, while a companion policy may abate emissions at a higher cost than carbon pricing, its use may be justified for the benefits offered toward non-climate objectives. Secondly, carbon pricing and companion policies have the potential to work in synergy, meaning that the abatement cost of the policy mix can be lower than that of any policy alone. The challenge lies in calibrating policies so as to realise this synergy, and not - to the contrary - increase the overall abatement cost. Thirdly, if carbon pricing beyond certain levels proves politically not feasible, companion policies can substitute for it. Furthermore, it has been argued that by expanding political support for carbon pricing, companion policies may help raise its level (Meckling et al., 2015). ${ }^{15}$ There follows a more detailed discussion of two of the rationales just mentioned.

Market and behavioural failures associated with technological change provide strong rationales for policies targeting innovation and adoption of low-carbon technologies, for example in the form of $\mathrm{R} \& \mathrm{D}$ subsidies and feed-in tariffs, in tandem with carbon pricing. As far as renewable energy is concerned, market failures primarily relate to knowledge spillovers (Gillingham and Sweeney, 2010). Essentially, market forces alone lead to suboptimal private investments in renewable energy because investors do not appropriate the social benefits of related knowledge spillovers. ${ }^{16}$ In the EE domain, suboptimal investments are also explained by market failures, which however mainly relate to information failures, split incentives (as with the 'landlord-tenant dilemma') and transaction costs, as well as by investors' bounded rationality (Linares and Labandeira, 2010). Several studies show that policy mixes inclusive of both carbon pricing and policies targeting one or more of said failures can achieve emission reductions at significantly lower costs than any single policy (Fischer and Newell, 2008; Fischer and Preonas, 2010; Acemoglou et al., 2012; Fischer et al., 2017).

\footnotetext{
${ }^{14}$ In the case of emissions trading, the equimarginal principle applies conditional on classical economic assumptions about the allowance market, notably: that market participants are rational and operate with perfect foresight, that information about prices and costs is complete, and that unlimited banking and borrowing are allowed (Acworth et al., 2017).

${ }^{15}$ Meckling et al. (2015: 1170): 'The more green industries form or expand, the stronger coalitions for decarbonizing energy systems become, and the easier it gets to install stronger or more comprehensive regulatory strategies'.

${ }^{16}$ Knowledge spillovers associated with renewable energy include 'learning-by-searching', 'learning-bydoing' and 'learning-by-using'. As learning-by-searching derives from research activities, publicly-funded $\mathrm{R} \& \mathrm{D}$ is the canonical policy response. Learning-by-doing and learning-by-using depend on accumulated experience in producing and using a technology, respectively. Greater production is expected to increase productivity and, hence, to reduce average unit costs. As to learning-by-using, this is especially relevant to technologies with complex and interdependent components. Support to technology deployment, via, e.g., feed-in tariffs or green certificates, is the corresponding policy response. The solar and wind industries are examples of drastically reduced unit production costs also thanks to enduring support.
} 
A second argument in favour of companion policies derives from the difficulty of imposing carbon prices that are sufficiently high and timely for deep cost-effective decarbonisation. In recent years, economists have given increasing consideration to this limitation of carbon pricing, which largely is a problem of political feasibility (HLCCP, 2017; Tvinnereim and Mehling, 2018; Hepburn et al., 2020). Insufficient carbon price levels, by delaying low-carbon investments, determine a lock-in of carbon-intensive infrastructure and ultimately greater decarbonisation costs (Unruh, 2000; Seto et al., 2016). This eventuality provides an economic rationale for companion policies which, by bringing about investments that otherwise would not materialise given insufficient carbon prices, can help achieve long-term abatement targets at lower societal cost (Vogt-Schilb and Hallegatte, 2014; Vogt-Schilb et al., 2018; Goulder, 2020).

\subsection{The waterbed effect and ETS design}

When it comes to companion policies, the main difference between a carbon tax and an ETS with fixed allowance supply is that, with the second, abatement of regulated emissions by companion policies is offset by increased emissions within the system. For this reason, an ETS de facto makes companion policies environmentally ineffective. The mechanics of the 'waterbed effect', as this is known, is simple: reduced emissions by companion policies determines an excess supply in allowances, which will be reabsorbed by increased demand from entities for whom 'emitting more (sooner or later in time) and buying allowances' becomes convenient (Böhringer et al., 2008; Böhringer and Rosendahl, 2010; Goulder and Stavins, 2011; Eichner and Pethig, 2019). The waterbed effect arises in any policy mix that includes an ETS with allowance supply that does not automatically adjust to abatement of regulated emissions by companion policies.

In an ETS, adjustments to allowance supply that are more or less effective in tackling waterbed effects can come about in different ways. With reference to an ETS that specifically is a cap-and-trade system, directly adjusting allowance supply in corresponding volumes, by tightening the cap or by cancelling allowances already in circulation, is the most obvious and also most effective option. In a tradable performance standards system, the corresponding measure would be tightening the emission efficiency benchmarks that are applied in allowance allocation. In existing ETSs, direct adjustments to the supply of allowances tend to be occasional events so as not to increase regulatory uncertainty. Partial remedies to waterbed effects of companion policies are offered instead by rule-based mechanisms, which an ETS may or may not have, and which normally are not conceived exclusively for this purpose. Increasingly, ETSs around the world are equipped with price floors. These are intended as a 'safety valve' against the risk that unanticipated changes in relevant factors, such as economic activity, energy prices and abatement technology costs, but also market distortions, related to, e.g., investors' myopia and policy uncertainty, drive allowance prices to excessively low (i.e., welfare-decreasing) levels (Burtraw and Keyes, 2018). ${ }^{17}$ When a price floor is operationalised through the cancellation of allowances, there is a permanent adjustment in allowance supply. As far as waterbed effects of companion policies are concerned, the limitation is that they are only addressed insomuch as companion policies drive allowance prices down and activate the floor.

\footnotetext{
${ }^{17}$ By the same token, a price ceiling represents a safety valve against the risk of excessively high abatement costs (see Jacoby and Ellerman, 2004; Burtraw et al., 2010). In a study of California's ETS, whose results may be extended to other ETSs, Borenstein et al. (2019) show ex-ante uncertainty to be so high that allowance prices are very likely to be determined by the system's price floor or ceiling.
} 
The MSR of the EU ETS provides an example - unique for now - of a different mechanism that partially addresses waterbed effects. Notably, the MSR withdraws allowances from future auctions and stores them in a reserve any time that market surplus exceeds a given threshold. ${ }^{18}$ Crucially, from 2023 onward, allowances in the reserve that exceed the previous year's auction volume will be cancelled. Because of the way this rule works, the MSR is only able to address waterbed effects as long as market surplus is above the threshold and allowances in the reserve exceed the previous year's auction volume. The ability of the MSR to address waterbed effects is therefore more and more limited over time as market surplus is progressively absorbed (Perino, 2018). In addition to allowance cancellation via the MSR, as of Phase IV member states can voluntarily cancel allowances from the auction volume available to them in case of closure of electricity generation capacity resulting from additional national measures. Thus, the waterbed effect can be perfectly defeated in this important - but special - case.

\section{Empirical ex-post evidence from the EU ETS}

To date, a modest amount of empirical ex-post evidence is available on the relative environmental or economic performance of the EU ETS and its companion policies in abating emissions, and even less so on the interactions within the policy mix. This section offers a summary of the relevant literature. A first group of works assess the extent to which observed emission reductions under the EU ETS can be attributed to companion policies - typically policies supporting RES electricity - rather than to carbon prices instated by the system. Other studies estimate abatement costs of policies supporting RES electricity generation differentiated by technology, thus providing metrics ('implicit or equivalent carbon prices') that can be compared with carbon prices. Finally, only one study, to our knowledge, quantifies the impacts of changes in RES electricity generation, and of other determinants of marginal abatement costs, on European Union allowance (EUA) prices.

\subsection{Abatement by companion policies}

Weigt et al. (2013) estimate the impacts of the EU ETS and of RES deployment on $\mathrm{CO}_{2}$ emissions in Germany's electricity sector, 2006-2010. Counterfactual scenarios are simulated using a unit commitment model, which is a plant-level model of the electricity system allowing simulation of electricity dispatch. The authors calculate that without new RES capacity and holding EUA prices at historical levels, emissions from the electricity sector would have been 11 to 20 per cent higher over the study period. In the opposite case, namely without the EU ETS (EUA prices being set to zero) and holding RES capacity at historical levels, emissions would have been 1 to 3 per cent higher. It is, thus, concluded that policies directly supporting RES deployment in the electricity sector were much more effective than the EU ETS in reducing emissions. An interesting result is also that of a small positive interaction between the two policies, as injections of RES electricity into the grid are found to abate fewer emissions (0.5-1.5 per cent less) when EUA prices are set to zero. ${ }^{19}$ Using a similar approach, Van den Bergh et al. (2013) estimate the impact of deployment of RES electricity on $\mathrm{CO}_{2}$ emissions of the electricity

\footnotetext{
${ }^{18}$ Conversely, more allowances are taken from the reserve and auctioned when market surplus falls below a lower threshold.

${ }^{19}$ The quantity of emissions abated through RES injections (into the grid) depends on which plants, at the margin of the merit order, are displaced. In the electricity system analysed, the interaction effect turns out
} 
sector in 12 member states, 2007-2010. The results show that without deployment of RES electricity attributed to support schemes, emissions of the electricity sector would have been 10 to 16 per cent higher across countries, over the study period.

Using a multi-country, multi-sector macro-econometric model of the global economy, Meyer and Meyer (2013) estimate the impacts of the EU ETS (EUA prices) and of policies supporting RES electricity on $\mathrm{CO}_{2}$ emissions as well as on GDP and employment. This is done for each and every member state, over the period 1998-2008. The model is calibrated to historical values of key macro-economic variables to derive the baseline against which the counterfactuals of interest are evaluated. Without the EU ETS, it is found, 2008 emissions would have been 1 to 3 per cent higher in most member states. The impacts on GDP and employment, however, would have been smaller. Turning to RES policies, two counterfactuals are considered. In both scenarios, capacity of RES electricity is fixed at 1998 levels and RES investment is replaced by investment in conventional generation. In one scenario, however, total investment is unchanged, while in the other it is crowded out. In the first case, Germany, Portugal and Spain would have had 9, 7.8 and 5.6 per cent more $\mathrm{CO}_{2}$ emissions in 2008, respectively. These are the largest variations, while the average is 2.5 per cent. The corresponding effects on economic activity and employment are small in size, as total investment is unchanged. By the same token, negative effects on GDP and employment prevail when total investment is crowded out. It is concluded that RES policies had positive effects on emission reductions and, also, that they probably had positive effects on GDP and employment in most European countries.

Gloaguen and Alberola (2013) assess econometrically the relative importance of different factors in explaining emissions from the sectors covered by the EU ETS, 2005-2011. A panel-data model, which includes the share of RES in electricity generation, economy's energy intensity, economic activity, as well as energy and carbon prices among other explanatory variables, is fitted to country-level annual emissions of all member states. The model reproduces the historical baseline sufficiently well and is, thus, used for performing counterfactual simulations. The authors calculate a reduction of 1.1 billion tonnes in regulated $\mathrm{CO}_{2}$ emissions. Over half of these reductions resulted from RES and EE policies. Substantially smaller are the estimated impacts of the economic downturn and of energy prices (substitution effects of coal and gas prices), which are estimated at around 300 and 200 million tonnes, respectively. ${ }^{20}$

\subsection{Abatement cost of companion policies}

A few studies have estimated the abatement costs of policies supporting RES electricity generation. For policies supporting different technologies, 'implicit or equivalent carbon prices' are estimated as measures of abatement cost comparable with carbon prices. Rey et al. (2013) is the first relevant European study. The authors estimate implicit carbon prices of policies supporting seven different technologies (hydro, wind, biomass, biogas, PV, geothermal and waste), in eight European countries. The analysis, which is carried out for year 2010, is methodologically simple. For a given policy and technology, the abatement cost is given by the ratio of (a) the average financial support to the technology

\footnotetext{
to be positive because, with carbon pricing, coal plants are more often at the margin of the merit order than they would be otherwise.

${ }^{20}$ The impact of EUA prices on emissions cannot be identified due to the insufficient number of data points.
} 
( $€ / \mathrm{MWh}$ ), to (b) the corresponding amount of avoided $\mathrm{CO}_{2}$ emissions. Emission reductions are estimated by applying average values of electricity $\mathrm{CO}_{2}$ intensity, and benefits in the form of fuel cost savings are not considered. The results vary widely across technologies and countries, reflecting different levels of financial support and types of energy mix. PV support exhibits by far the highest abatement costs, with values over $€ 700 / \mathrm{tCO}_{2}$ in most countries. As to the other technologies, abatement costs always exceed $€ 50 / \mathrm{tCO}_{2}$ (with the striking exception of wind in the Czech Republic) and in most cases fall in the range between $€ 100$ and $€ 200 / \mathrm{tCO}_{2}$.

More recent studies highlight how implicit carbon prices depend on several factors, but primarily on the generosity of subsidies to electricity generation and on the type of conventional generation displaced by RES injections. Using a unit commitment model of Germany's electricity system, Marcantonini and Ellerman (2016) estimate implicit carbon prices for subsidies to wind and PV generation in that country, over 2006-2010. The implicit carbon price is calculated as the ratio of net costs to emission reductions, both as related to generation of RES electricity. With reference to net costs, the remuneration of electricity generation, which includes a feed-in tariff, is the main cost component; fuel cost savings, achieved by the displacement of conventional generation, represent the main benefit component. Both fuel cost savings and emission reductions are derived through simulations of the national electricity system. For support to wind generation, the implicit carbon price is found to average $€ 57 / \mathrm{tCO}_{2}$ over $2006-2010$. For PV generation, the implicit carbon price is much higher, averaging $€ 552 / \mathrm{tCO}_{2}$ over the same period. Using the same approach, Marcantonini and Valero (2017) estimate implicit carbon prices for subsidies to wind and PV generation in Italy, 2008-2011. Compared to the results for Germany in the previous study, implicit carbon prices turn out to be much higher, averaging $€ 165 / \mathrm{tCO}_{2}$ and $€ 1000 / \mathrm{tCO}_{2}$ for wind and $\mathrm{PV}$, respectively. Further, addressing the same question but using an econometric approach, Abrell et al. (2019) estimate implicit carbon prices for subsidies to wind and PV generation in Germany (2010-2015) and Spain (2014-2015). For wind subsidies, estimated implicit carbon prices range from $€ 105$ to $€ 276 / \mathrm{tCO}_{2}$ and from $€ 82$ to $€ 258 / \mathrm{tCO}_{2}$ in Germany and Spain, respectively; for PV subsidies, they range from $€ 411$ to $€ 972 / \mathrm{tCO}_{2}$ and from $€ 784$ to $€ 1944 / \mathrm{tCO}_{2}$, in the same country order.

\subsection{Impact of companion policies on allowance prices}

Using time series analysis and EU-level monthly data, Koch et al. (2014) investigate the relative importance of different factors in explaining the dynamics of EUA prices. The factors considered are: (a) relative prices of natural gas and coal, (b) expectations on economic activity (as proxied by returns of the STOXX EUROPE 600 stock index and, alternatively, by changes in the Eurostat Economic Sentiment Indicator), (c) growth of RES electricity generation (hydro, wind and PV), and (d) use of international offsets (as proxied by the number of issued Certified Emission Reductions ${ }^{21}$ ). The authors analyse the period 2008-2013, a time interval during which carbon prices fell from almost $€ 30$, in mid-2008, to less than $€ 5$, in mid-2013. The main finding is that only about 10 per cent of the variation in EUA prices can be explained by the four variables of interest, which are abatement-related fundamentals of allowance prices. Within this 10 per cent,

\footnotetext{
${ }^{21}$ Certified Emission Reductions (CERs), which are issued under the Kyoto Protocol's Clean Development Mechanism, can be used for compliance in the EU ETS (not as of Phase IV anymore). Their use affects EUA prices because it implies a reduction in the demand for EUAs.
} 
40 per cent of the variation in carbon prices is attributed to changes in expected economic conditions and about 25 per cent to generation of RES electricity. The fact that EUA price dynamics is only to a small extent explained by marginal abatement cost theory points to the importance of other factors in price formation, including notably regulatory uncertainty - as shown analytically by Salant (2016) and confirmed empirically by Koch et al. (2016) - and financial trading motives (Friedrich et al., 2020). However, the small estimated effect of RES electricity generation on EUA prices does not disprove, in our view, the relevance of negative interactions between companion policies and the EU ETS. One reason is that the model is estimated using monthly data, and so it captures very short-term effects. A second one is that, given well-known long-term binding targets for renewable energy, market participants may have expected the expansion of RES electricity and, if so, allowance demand had already factored it in.

\section{Insights for China's ETS}

Based on the summaries of the EU's and China's climate policies and of both relevant theory and empirical evidence concerning the EU ETS and its companion policies, we discuss insights that may be relevant to China's forthcoming ETS. The discussion focuses on three themes: the ways waterbed effects may arise in China's ETS, the calibration of the policy mix, and adjustments to allowance supply.

\subsection{Waterbed effects in China's ETS}

To understand how companion policies might interact with China's ETS, the rules for allowance allocation are the starting point. Every year, each regulated firm will receive an allocation equal to its annual output multiplied by a predetermined benchmark for output emission efficiency. The total number of allowances issued in a given year will therefore depend on current output levels and predetermined benchmarks. For our purposes, this implies that allowance supply will automatically adjust for companion policies insomuch as they affect regulated firms' output. Policies that support RES electricity and result in displaced fossil-based generation are probably the most relevant example. Thus, insomuch as output is affected, waterbed effects will not arise and companion policies will be environmentally effective. This is an important difference from ETSs with fixed allowance supply.

China's ETS will not be immune from waterbed effects, however. The reason is allowance supply will not automatically adjust for any of those policies that have a direct or indirect effect on regulated firms' emission efficiency. Examples of such policies include emission standards, EE policies and local pollution policies. While environmentally effective to the extent that they reduce regulated firms' output, policies supporting RES electricity will also generate waterbed effects. In China's ETS, indirect emissions of grid operators and of large electricity consumers will be covered by allocations calculated by applying predetermined emission factors. Expansion of RES electricity, however, implies that indirect emissions will actually decrease. ${ }^{22}$ Therefore, unless the benchmarks applied in allowance allocation already factor in future progress in emission efficiency, or they are revised when efficiency improvements take place, waterbed effects will arise. If so, said policies will not be environmentally effective and will put downward

\footnotetext{
${ }^{22}$ We thank Duan Maosheng for pointing out to us this channel for waterbed effects of policies expanding RES electricity generation.
} 
pressure on prices by reducing allowance demand. This is no different from ETSs with fixed allowance supply.

\subsection{Careful calibration of the policy mix}

Careful calibration of carbon pricing and companion policies is key to minimising the cost of achieving a given abatement level. Good calibration of companion policies produces a synergy with carbon pricing whereby the abatement cost of the policy mix is lower than that of carbon pricing alone. Conversely, excessive use of companion policies raises the abatement cost of the policy mix above that of carbon pricing alone. If carbon pricing is more specifically implemented through an ETS, carbon prices are endogenous in the calibration exercise, given the interactions between a quantity-based instrument and other instruments.

While the EU is on track to meet its 2020 targets for renewable emissions, renewable energy and EE, corresponding policies adopted by some member states, especially subsidies to RES electricity generation, have been criticised for being overly generous. The environmental inefficacy of these policies, because of the EU ETS and the waterbed effect, and their contribution to further lowering EUA prices, added to the criticism. The empirical evidence summarised in section 4, which mainly covers the first two trading periods of the EU ETS, clearly shows that: (a) emissions in the electricity sector were primarily abated by companion policies, rather than by carbon prices, and (b) that their abatement costs were much higher than concurrent carbon prices. Later, in Spain, Italy and other member states, financial support to RES electricity was substantially reduced, though primarily because the total cost was becoming unsustainable.

Carefully calibrating companion policies together with an appropriate carbon price signal, is a general recommendation reaffirmed by the EU's experience. At least two specific considerations can be made. First, clarity is desirable about the different objectives pursued by a mix of climate and energy policies. In Europe, greater clarity in this respect would help evaluate large differences in abatement costs between RES policies and the EU ETS, and make adjustments if needed. Incidentally, we are not aware of studies estimating implicit carbon prices of EE policies in the European context, which seems quite a knowledge gap. Second, economists stress the importance of calibrating support policies in function of the size of market failures, which in the RES and EE domains mainly relate to knowledge spillovers and imperfect demand, respectively. In the past two decades, the EU has by far privileged support to adoption of RES technologies rather than to innovation. This has raised calls for a rebalancing of policy support toward innovation (Dechezleprêtre and Popp, 2015). Such recalibration is warranted by mature technologies approaching grid parity and by deep decarbonisation demanding other technologies that are still overly expensive.

\subsection{Permanent adjustments to allowance supply}

Adjusting allowance supply of an ETS, to eliminate or reduce unanticipated waterbed effects, can be considered for environmental reasons, namely, abating more emissions by making the corresponding policies environmentally effective. It can also be considered if current allowance prices are deemed too low, in the sense that they undermine the dynamic cost effectiveness of the system (Fuss et al., 2018). In such a situation, the concern is that a prolonged period of low prices would lead to a lock-in of carbon-intensive infrastructure and ultimately higher abatement costs. To the extent that low prices 
are due to a supply-demand imbalance, adjusting supply is an appropriate response. ${ }^{23}$ The experience of the EU ETS, however, suggests that these adjustments need be permanent (i.e., cap affecting) if they are to be effective. In other words, mere temporary variations in allowance scarcity do not work.

Among the problems faced by the EU ETS since its inception, low EUA prices for several years has probably been the most serious. The accumulation of a massive and persistent market surplus, while not being the only possible driver, likely explains much of the low prices observed in the recent past. It all started with the economic recession of 2008-2009, which caused a major fall in regulated emissions and, therefore, in allowance demand (Bel and Joseph, 2015; Chèze et al., 2020). Companion policies of the EU ETS and the inflow of international offset contributed to the build-up of the market surplus, but to a lesser extent (de Perthuis and Trotignon, 2014). When the cap for Phase III was set, both expected expansion of renewable energy and expected improvements in $\mathrm{EE}$ were factored in on the basis of the respective 2020 targets. However, progress in EE was not fully accounted for, nor was the use of cheap international offsets for compliance purposes, which de facto acted as a supply increase (Jalard et al., 2015). By the start of Phase III, a market surplus of about two billion allowances had been accumulated. To give an idea of the significance of this imbalance, it exceeded the total annual volume of regulated emissions. Between 2012 and 2018, EUA prices stayed well below $€ 10$ most of the time, with occasional dips below $€ 5$. Such prices were much lower than those indicated by simulation models as being 'optimal' in a dynamic cost-effective sense. ${ }^{24}$

The European Commission intervened three times to address the issue, in three different ways: in 2012, the auctioning of 900 million allowances was 'backloaded' (i.e., postponed) from 2014-2015 to 2019-2020; in 2015, the MSR was established, which as of 2019 would start withdrawing allowances from future auctions; and in 2018, as part of the reform for Phase IV, both the future cap trajectory was tightened up and the MSR mechanism was enhanced via a higher intake rate and a rule enabling the cancellation of the allowances stored in the MSR in excess of the previous year's auction volume. Only the third intervention, the only one to involve a permanent adjustment to allowance supply, both through the tightened cap and the enhanced MSR, had the desired effect. The mere expectation of the adjustment was sufficient for prices to quickly return to values between $€ 25$ and $€ 30$. $^{25}$ This short series of events suggests that only permanent adjustments to allowance supply are effective in influencing prices. In China's ETS, permanent adjustments to allowance supply will be implemented through revisions of the efficiency benchmarks applied in allowance allocation - akin to cap changes in the EU ETS. Besides, China's ETS will be equipped with a price floor, which could involve allowance cancellation and, therefore, permanent supply adjustments. Yet, the details of its operation are not yet known.

\footnotetext{
${ }^{23}$ Inspired by chronically low prices in the EU ETS, recent literature (e.g., Salant, 2016; Acworth et al., 2017; Edenhofer et al., 2018; Fuss et al., 2018; Pahle et al., 2018; Flachsland et al., 2020) stresses the role that market distortions, related to regulatory uncertainty, myopia and excessive discounting of market participants, can have in explaining low allowance prices.

${ }^{24}$ The PRIMES model, one of the most used by the European Commission for its impact assessments of EU ETS reforms, had estimated optimal carbon prices (i.e., minimising the cost of achieving long-term abatement targets) to be $€ 25$ in 2020 and $€ 50$ in 2030 (Fuss et al., 2018).

${ }^{25}$ Quemin (2020) disentangles the effects of the tightened cap and of the enhanced MSR on the price recovery.
} 


\section{Conclusions}

There is great anticipation worldwide for the start of China's ETS. It will be a key tool for the Chinese government to achieve climate mitigation targets at minimum cost, but also a possible catalyst and a blueprint for new ETSs in developing economies. As with any major ETS for climate mitigation, the economic success of China's ETS, and of China's climate action more generally, will partly depend on how well the system and its companion policies will be coordinated and work in synergy.

In this paper, we have asked ourselves whether the European experience with the EU ETS and its companion policies may offer useful insights for China's forthcoming system. Our analysis firstly showed that China's ETS, despite fundamental design differences with the EU ETS (in particular, the fact that allowance supply automatically adjusts to output levels of regulated firms), will not be immune to waterbed effects of companion policies. We then made recommendations based on the European experience regarding the calibration of the policy mix. In particular, we stressed, on the one hand, the importance of making explicit the objectives pursued by companion policies that are different from climate mitigation; on the other, we emphasised the importance of seeking an economically-efficient balance between policies supporting innovation of emission abatement technologies and those supporting the adoption of abatement technologies. Furthermore, we identified an insight regarding the control of allowance prices when they are depressed by a supply-demand imbalance, whether this was in turn caused by unanticipated companion policies or other shocks. The history of the EU ETS suggests that adjustments to allowance supply that are only temporary are not effective.

Finally, the paper does not consider aspects relating to the governance of a complex policy mix, which as explained by Duan et al. (2017) are very relevant to China's climate policy mix. Here too, the European experience could offer useful insights. However, identifying them and evaluating their actual transferability to the Chinese context requires an in-depth analysis of both institutional frameworks which is beyond the paper's scope.

Acknowledgments. The authors would like to thank two anonymous reviewers for their helpful comments and constructive suggestions. Any remaining errors are the sole responsibility of the authors. The work leading to this study was co-financed by the EU LIFE Programme of the European Commission Grant Agreement LIFE15 GIC/IT/000051 LIFE SIDE. This paper reflects only the authors' view and the Agency is not responsible for any use that may be made of the information it contains.

\section{References}

Abrell J, Kosch M and Rausch S (2019) Carbon abatement with renewables: evaluating wind and solar subsidies in Germany and Spain. Journal of Public Economics 169, 172-202.

Acemoglou D, Aghion P, Bursztyn L and Hemous D (2012) The environment and directed technical change. American Economic Review 102, 131-166.

Acworth W, Ackva J, Burtraw D, Edenhofer O, Fuss S, Flachsland C, Haug C, Koch N, Kornek U, Knopf B and Montes de Oca M (2017) Emissions Trading and the Role of A Long run Carbon Price Signal: Achieving Cost Effective Emission Reductions Under an Emissions Trading System. Berlin: ICAP.

Acworth W, Montes de Oca M, Gagnon-Lebrun F, Gass P, Matthes F, Piantieri C and Touchette Y (2018) Emissions Trading and Electricity Sector Regulation. Berlin: ICAP.

Bel G and Joseph S (2015) Emission abatement: untangling the impacts of the EU ETS and the economic crisis. Energy Economics 49, 531-539.

Böhringer C and Rosendahl KE (2010) Green promotes the dirtiest: on the interaction between black and green quotas in energy markets. Journal of Regulatory Economics 37, 316-325. 
Böhringer C, Koschel H and Moslener U (2008) Efficiency losses from overlapping regulation of EU carbon emissions. Journal of Regulatory Economics 33, 299-317.

Borenstein S, Bushnell J, Wolak FA and Zaragoza-Watkins M (2019) Expecting the unexpected: emissions uncertainty and environmental market design. American Economic Review 109, 3953-3977.

Boute A (2017) The impossible transplant of the EU Emissions Trading Scheme: the challenge of energy market regulation. Transnational Environmental Law 6, 59-85.

Burtraw D and Keyes A (2018) Recognizing gravity as a strong force in atmosphere emissions markets. Agricultural and Resource Economics Review 47, 201-219.

Burtraw D, Palmer K and Kahn D (2010) A symmetric safety valve. Energy Policy 38, 4921-4932.

Chèze B, Chevallier J, Berghmans $\mathbf{N}$ and Alberola $\mathrm{E}$ (2020) On the $\mathrm{CO}_{2}$ emissions determinants during the EU ETS Phases I and II: a plant-level analysis merging the EUTL and Platts power data. Journal of the IAEE's Energy Economics Education Foundation 41, 153-183.

Dechezleprêtre A and Popp D (2015) Fiscal and Regulatory Instruments for Clean Technology Development in the European Union. London: ESRC Centre for Climate Change Economics and Policy and Grantham Research Institute on Climate Change and the Environment.

De Gouvello C, Finon D and Guigon P (2019) Reconciling Carbon Pricing and Energy Policies in Developing Countries - Integrating Policies for A Clean Energy Transition. World Bank, Washington, DC.

Deng M and Zhang WX (2019) Recognition and analysis of potential risks in China's carbon emission trading markets. Advances in Climate Change Research 10, 30-46.

De Perthuis $\mathbf{C}$ and Trotignon $\mathbf{R}$ (2014) Governance of $\mathrm{CO}_{2}$ markets: lessons from the EU ETS. Energy Policy 75, 100-106.

Duan M, Tian Z, Zhao Y and Li M (2017) Interactions and coordination between carbon emissions trading and other direct carbon mitigation policies in China. Energy Research \& Social Science 33, 59-69.

Edenhofer O, Flachsland C, Wolff C, Schmid LK, Leipprand A, Koch N, Kornek U and Pahle M (2018) Decarbonization and EU ETS Reform: Introducing A Price Floor to Drive Low-Carbon Investments. Berlin: Mercator Research Institute on Global Commons and Climate Change.

EEA (2019) Trends and Projections in Europe 2019. Tracking Progress Towards Europe's Climate and Energy Targets. Luxembourg: European Environment Agency, Publications Office of the European Union. Available at https://www.eea.europa.eu/publications/trends-and-projections-in-europe- 1 .

Eichner T and Pethig R (2019) EU-type carbon regulation and the waterbed effect of green energy promotion. Energy Economics 80, 656-679.

European Commission (2018) Communication from the Commission to the European Parliament, the Council the European Economic and Social Committee and the Committee of the Regions and the European Investment Bank. A Clean Planet for all - A European strategic long-term vision for a prosperous, modern, competitive and climate neutral economy. $\operatorname{COM}(2018) 773$ final. Brussels: European Commission.

European Commission (2019) Communication from the Commission to the European Parliament, the European Council, the Council, the European Economic and Social Committee and the Committee of the Regions, the European Green Deal. COM(2019) 640 final. Brussels: European Commission.

European Parliament and Council (2012) Directive 2012/27/EU of the European Parliament and of the Council of 25 October 2012 on energy efficiency, amending Directives 2009/125/EC and 2010/30/EU and repealing Directives 2004/8/EC and 2006/32/EC. Brussels: European Parliament and Council.

Eurostat (2020) Energy, Transport and Environment Statistics. Luxembourg: Publications Office of the European Union. Available at https://ec.europa.eu/eurostat/documents/3217494/11478276/ KS-DK-20-001-EN-N.pdf/06ddaf8d-1745-76b5-838e-013524781340.

Fischer C (2001) Rebating environmental policy revenues: output-based allocations and tradable performance standards. Resources for the Future Discussion Paper 01-22, Washington, DC.

Fischer C and Newell RG (2008) Environmental and technology policies for climate mitigation. Journal of Environmental Economics and Management 55, 142-162.

Fischer C and Preonas L (2010) Combining policies for renewable energy: is the whole less than the sum of its parts? International Review of Environmental and Resource Economics 4, 51-92.

Fischer C, Preonas L and Newell RG (2017) Environmental and technology policy options in the electricity sector: are we deploying too many? Journal of the Association of Environmental and Resource Economists 4, 959-984. 
Flachsland C, Pahle M, Burtraw D, Edenhofer O, Elkerbout M, Fischer C, Tietjen O and Zetterberg L (2020) How to avoid history repeating itself: the case for an EU Emissions Trading System (EU ETS) price floor revisited. Climate Policy 20, 133-142.

Friedrich M, Mauer E, Pahle M and Tietjen O (2020) From Fundamentals to Financial Assets: The Evolution of Understanding Price Formation in the EU ETS. Kiel, Hamburg: ZBW - Leibniz Information Centre for Economics.

Fuss S, Flachsland C, Koch N, Kornek U, Knopf B and Edenhofer O (2018) A framework for assessing the performance of cap-and-trade systems: insights from the European Union Emissions Trading System. Review of Environmental Economics and Policy 12, 220-241.

Gallagher KS and Xuan X (2019) Titans of the Climate: Explaining Policy Process in the United States and China. Cambridge: MIT Press.

Gillingham K and Sweeney JL (2010) Market failure and the structure of externalities. In Boaz M, Padilla J and Schmalensee R (eds), Harnessing Renewable Energy in Electric Power Systems: Theory, Practice, Policy. New York: Routledge, pp. 69-93.

Gloaguen $\mathbf{O}$ and Alberola E (2013) Assessing the factors behind $\mathrm{CO}_{2}$ emissions changes over the phases 1 and 2 of the EU ETS: an econometric analysis. Working paper 2013-05, CDC Climate Research.

Goulder LH (2020) Timing is everything: how economists can better address the urgency of stronger climate policy. Review of Environmental Economics and Policy 14, 143-156.

Goulder LH and Stavins RN (2011) Challenges from state-federal interactions in US climate change policy. American Economic Review: Papers \& Proceedings 101, 253-257.

Goulder LH, Long X, Lu J and Morgenstern RD (2019) China's unconventional nationwide $\mathrm{CO}_{2}$ Emis- $^{-}$ sions Trading System: the wide-ranging impacts of an implicit output subsidy. NBER working paper 26537. Cambridge, MA: National Bureau of Economic Research.

Hepburn C, Stern N and Stiglitz JE (2020) "Carbon pricing” special issue in the European Economic Review. European Economic Review 127, 103440.

HLCCP (2017) Report of the High-Level Commission on Carbon Prices. Washington, DC: World Bank. Available at https://static1.squarespace.com/static/54ff9c5ce4b0a53decccfb4c/t/59b7f2409f8dce5316811 916/1505227332748/CarbonPricing_FullReport.pdf.

Hu J, Kahrl F, Yan Q and Wang X (2012) The impact of China's differential electricity pricing policy on power sector $\mathrm{CO}_{2}$ emissions. Energy Policy 45, 412-419.

ICAP (2020) Emissions Trading Worldwide: Status Report 2020. Berlin : International Carbon Action Partnership.

IEA (2020) China's Emissions Trading Scheme. Paris: International Energy Agency.

Jacoby HD and Ellerman AD (2004) The safety valve and climate policy. Energy Policy 32, 481-491.

Jalard M, Dahan L, Alberola E, Cail S and Keramidas K (2015) The EU ETS emissions reduction target and interactions with energy and climate policies. In I4CE (ed.), Exploring the EU ETS Beyond 2020, Paris, 17-32. https://www.i4ce.org/wp-core/wp-content/uploads/2015/11/ 15-11-30-COPEC-FULL-REPORT.pdf.

Koch N, Fuss S, Grosjean G and Edenhofer O (2014) Causes of the EU ETS price drop: recession, CDM, renewable policies or a bit of everything? New evidence. Energy Policy 73, 676-685.

Koch N, Grosjean G, Fuss S and Edenhofer O (2016) Politics matters: regulatory events as catalysts for price formation under cap-and-trade. Journal of Environmental Economics and Management 78, 121-139.

Li L and Taeihagh A (2020) An in-depth analysis of the evolution of the policy mix for the sustainable energy transition in China from 1981 to 2020. Applied Energy 263, 114611.

Linares P and Labandeira X (2010) Energy efficiency: economics and policy. Journal of Economic Surveys 24, 573-592.

Marcantonini C and Ellerman D (2016) The implicit carbon price of renewable energy incentives in Germany. Energy Journal 36, 205-239.

Marcantonini C and Valero V (2017) Renewable energy and $\mathrm{CO}_{2}$ abatement in Italy. Energy Policy 106, $600-613$.

McWilliams B and Zachmann G (2020) Bruegel Electricity Tracker of COVID-19 Lockdown Effects. Brussels: Bruegel Datasets. Available at https://www.bruegel.org/2020/03/covid-19-crisiselectricity-demand-as-areal-time-indicator.

Meckling J, Kelsey N, Biber E and Zysman J (2015) Winning coalitions for climate policy. Green industrial policy builds support for carbon regulation. Climate Change 349, 1170-1171. 
Meyer B and Meyer M (2013) Impact of the current economic instruments on economic activity. Understanding the existing climate policy mix, CECILIA 2050 WP2 Deliverable 2.6. Osnabrück: Gesellschaft für Wirtschaftliche Strukturforschung (GWS).

Pahle M, Burtraw D, Tietjen O, Flachsland C and Edenhofer O (2018) Unilateral action under an emissions cap. Paper presented at the ASSA Annual Meeting 2019, 4-6 January 2018, Atlanta, GA.

Perino G (2018) New EU ETS Phase 4 rules temporarily puncture waterbed. Nature Climate Change 8, 260-271.

Perino G and Willner M (2016) Procrastinating reform: the impact of the market stability reserve on the EU ETS. Journal of Environmental Economics and Management 80, 37-52.

Perino G and Willner M (2017) EU-ETS Phase IV: allowance prices, design choices and the market stability reserve. Climate Policy 17, 936-946.

Quemin S (2020) Using supply-side policies to raise ambition: the case of the EU ETS and the 2021 Review. Grantham Research Institute on Climate Change and the Environment Working Paper 335, London School of Economics.

Rey L, Markandya A, González-Eguino M and Drummond P (2013) Assessing interaction between instruments and the "optimality" of the current instrument mix. CECILIA 2050 WP1 Deliverable 1.3. Bilbao: Basque Centre for Climate Change (BC3), London: University College London (UCL).

Salant SW (2016) What ails the European Union's emissions trading system? Journal of Environmental Economics and Management 80, 6-19.

Sandalow D (2019) 2019 Guide to Chinese Climate Policy. New York: Columbia Center on Global Energy Policy.

Schmalensee R and Stavins RN (2017) The design of environmental markets: what have we learned from experience with cap and trade? Oxford Review of Economic Policy 33, 572-588.

Seto KC, Davis SJ, Mitchell RB, Stokes EC, Unruh G and Ürge-Vorsatz D (2016) Carbon lock-in: types, causes, and policy implications. Annual Review of Environment and Resources 41, 425-452.

Tvinnereim E and Mehling M (2018) Carbon pricing and deep decarbonisation. Energy Policy 121, $185-189$.

Unruh GC (2000) Understanding carbon lock-in. Energy Policy 28, 817-830.

Van den Bergh K, Delarue E and D'haeseleer W (2013) Impact of renewables deployment on the $\mathrm{CO}_{2}$ price and the $\mathrm{CO}_{2}$ emissions in the European electricity sector. Energy Policy 63, 1021-1031.

Verde SF, Teixidó J, Marcantonini C and Labandeira X (2018) Free allocation rules in the EU emissions trading system: what does the empirical literature show? Climate Policy 19, 439-452.

Vogt-Schilb A and Hallegatte S (2014) Marginal abatement cost curves and the optimal timing of mitigation measures. Energy Policy 66, 645-653.

Vogt-Schilb A, Meunier G and Hallegatte S (2018) When starting with the most expensive option makes sense: optimal timing, cost and sectoral allocation of abatement investment. Journal of Environmental Economics and Management 88, 210-233.

Wang W, Xie P, Wang W and Zhao D (2019) Overview and evaluation of the mitigation efficiency for China's seven pilot ETS. Energy Sources, Part A: Recovery, Utilization, and Environmental Effects 1-15. doi: 10.1080/15567036.2019.1646352.

Wang B, Boute A and Tan X (2020) Price stabilization mechanisms in China's pilot emissions trading schemes: design and performance. Climate Policy 20, 46-59.

Weigt H, Ellerman D and Delarue E (2013) $\mathrm{CO}_{2}$ Abatement from renewables in the German electricity sector: does a $\mathrm{CO}_{2}$ price help? Energy Economics 40, S149-S158.

Zhang H, Duan M and Deng Z (2019) Have China's pilot emissions trading schemes promoted carbon emission reductions? The evidence from industrial sub-sectors at the provincial level. Journal of Cleaner Production 234, 912-924.

Cite this article: Verde SF, Galdi G, Alloisio I, Borghesi S (2021). The EU ETS and its companion policies: any insight for China's ETS?. Environment and Development Economics 26, 302-320. https://doi.org/10. 1017/S1355770X20000595 